\title{
Cooperative learning and brainstorming as didactic strategies in conservation and restoration of cultural assets
}

\author{
María-Ángeles Carabal-Montagud ${ }^{a}$, Virginia Santamarina-Campos ${ }^{\mathrm{b}}$, María Victoria \\ Esgueva López ${ }^{c}$, Sofía Vicente Palomino ${ }^{\mathrm{d}}$ \\ ${ }^{a}$ Universitat Politècnica de València, València, Spain, macamon@crbc.upv.es ${ }^{b}$ Universitat Politècnica \\ de València, València, Spain, virsanca@crbc.upv.es, ${ }^{c}$ Universitat Politècnica de València, València, \\ Spain, maeslo2@dib.upv.es, ${ }^{\mathrm{d}}$ Universitat Politècnica de València, València, Spain, \\ svicente@crbc.upv.es
}

\begin{abstract}
This article exposes the tools of cooperative learning and brainstorming as a didactic strategy, in which teamwork, diversity, interaction between the students and feedback between them are promoted as the main source of learning. In professions related to the conservation and restoration of cultural assets, we work as a team, thus is fundamental that the students' training prepares them for this work reality and enables them to be part of and lead these teams, fostering cross-cutting skills such as communication effective, critical thinking, application and practical thinking among others. We will present the case of a teaching experience, in which cooperative learning is a fundamental tool to solve one of the practices of the subject "Introduction to the Conservation and Restoration of golds and polychromies" of the Degree in Conservation and Restoration of Cultural Assets in Universitat Politècnica de València. The practice consists in the identification of manufacturing techniques, and focuses on the subsequent professionalization and comprehensive training of students. The results obtained from it show how peer learning is an effective, dynamic strategy with infinite possibilities.
\end{abstract}

Keywords: cooperative learning, brainstorming, training, peer learning 


\section{Introduction}

The following article is presented in the framework of the "Equipo de Innovación $y$ Calidad Educativa EICE "AFA-Realidad El proceso de Enseñanza y Aprendizaje Fuera de las Aulas - Baños de Realidad", from the Educational Science Institute of the Universitat Politècnica de València.

In this case this work is focused on the analysis of the results obtained from this educational innovation from the subject Introduction to the Conservation and Restoration of golds and polychromies" (cód.14068) of the Degree in Conservation and Restoration of Cultural Assets in Universitat Politècnica de València.

A teaching experience case will be presented, in which cooperative learning is a fundamental tool to solve one of the practices of the subject itself, which consists in the identification of manufacturing techniques, and focuses on the subsequent professionalization and integral formation of the students. "We can say, that collaborative learning in university education is presented as a methodological alternative to individualistic models that are little creative and reflective, typical of traditional methodologies." (Guerra et al., 2018).

The main aim of this article is to analyse the results obtained from encouraging the use of alternative teaching strategies based on active methodologies, through a technological and cultural social immersion that enhances continuous learning. For this type of teaching innovation, special emphasis has been placed on group work and contact with real cases in which students will find themselves in their future career.

We draw from the premise that motivation is the learner's engine (Ospina Rodríguez, 2006). Following this practice it is proposed to test the scope of the same, taking into account the motivation that it can generate within the students, by considering their specific concerns and interests, which in the vast majority of cases they are focused on their later career, making them strengthen critical thinking focusing on the real needs which they will encounter when they finish their studies.

The implementation of the proposed activities in the involved subjects in the project encourages the acquisition of the following transversal competences: Understanding and integration, Innovation, creativity and entrepreneurship, Design and project, Effective communication and knowledge and awareness of contemporary problems. 


\section{Main Goals}

- Expose the results obtained from the use of the tool of cooperative learning as a didactic strategy.

- Involve students in proposals they will face in their future work career, relating them to the theory and practice developed in the classroom, working on their skills related to autonomy and professionalization.

- $\quad$ Reflect on the need of implementing inclusive activities, taking into account the students' opinion, and their advantages by feeling themselves as leaders in their own learning, as a strategy for content integration.

- To provide students with an analytical view of the contents worked, so that they can develop their practical and critical thinking in real areas, promoting efficient communication.

- Promote interaction among students, teamwork, development of cooperative methodologies, leadership and problem solving.

- Promote equal conditions, diversity and parity in the different resolutions related to the activity.

- Promote feedback, after the use of brainstorming, as the main source of learning, as a result of a first working session.

- Transfer the results of such a teaching strategy to the university community.

\section{Methodology}

\section{HEURISTIC PHASE}

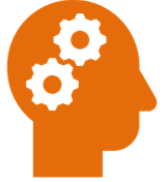

Analysis of specific needs

Selection of work objects

Work teams
ANALYTHICAL PHASE

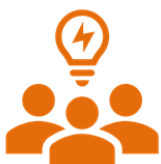

Discussion

Proposal of the activity

Development
SYNTHETIC PHASE

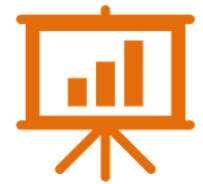

Resolution

Results evaluation

Improvement proposals

Fig. 1 Methodology

Font: Own font 


\subsection{Heuristic Phase}

1. Firstly, an analysis of the specific needs in the subject, Introduction to the Conservation and Restoration of golds and polychromies, which were related to the second part of the curriculum, linked to conservation and restoration. The purpose of the practice was to work on the contents that were intended to be strengthened in a real way. With this, the experience was practical and contained without directly making interventions on the subject, but proposals, doubts and real situations were generated, with which a conservative-cultural property restorer can be found in your future work.

2. Selection and numbering of work objects. In our case we work with golden frames, of royal collections, which are currently in our department to be restored, together with the pieces of work that they frame. Firstly, a classification of all the available frames was made, and then we selected those that we consider most appropriate to discriminate between the gilding techniques with which they were made. Gold frames with various metal sheets were also selected to make its identification more difficult.They were numbered to have a code to reference each of them during practice.

3. Division of students by heterogeneous groups in arbitrary order, ensuring that the groups did not coincide with those who had worked together in previous sessions. Working with heterogeneous groups is essential, since within Cooperative learning "the formation of collaborative groups is based on the heterogeneity of knowledge, skills, values, previous ways of acting and thinking, as well as social and behavioral skills, gender, age, etc." (Rodriguez et al., 2005).

There are a total of 45 students enrolled in the subject. The number of members in a group, when going to work with brainstorming is decisive for obtaining results. As determined by the study conducted by Paulus et al. "One of the most influential factors in brainstorming is the size of the group (...) larger groups do provide more potential for exchange of a large number of ideas from a diverse group of individuals.However, the problem of Production blocking increases with group size, especially in groups that share ideas verbally. Thus the larger the group, the lower will be the number of ideas per person. The optimal group size is two." (Paulus et al., 2019). Faced with the impossibility of making groups of two with 45 people, 15 groups of 3 people were made.

\subsection{Analythical Phase}

1. Team discussion about the results they expect from the practice. According to Esteban García and Ortega Gutiérrez, "Using the debate can be a very useful strategy for the intellectual development of the student and for connecting university issues with social 
problems" (Esteban et al, 2017). In this first step, the teachers through observation, carried out a sweep of the opinions of the different teams, also taking into account the assessment between groups.

2. Proposal for the activity to be carried out. The proposal of activity drawn up consisted of three phases; work and individual reflection, the pooling as main strategy and brainstorming. All of them converged in Cooperative learning,since learning was between equals.

3. Development of the activity.

\subsubsection{Individual work and reflection}

Bearing in mind that "collaborative learning is from individual reflection to group reflection and from this to the enriched individual reflection" (Rodríguez et al., op cit., 2005), an opportune time was given for the students' individual reflection.

\subsubsection{Putting teams together and brainstorming.}

When the students were clear about their hypotheses, regarding the practice, they put everything in common, through the technique of brainstorming, trying to understand the technique of gilding of the frames and the materials used for it. The data that each of them was appointing, in practice, was being recorded in a portfolio that the faculty had prepared, with the questions they had to discuss and the aspects to which they had to pay attention to.

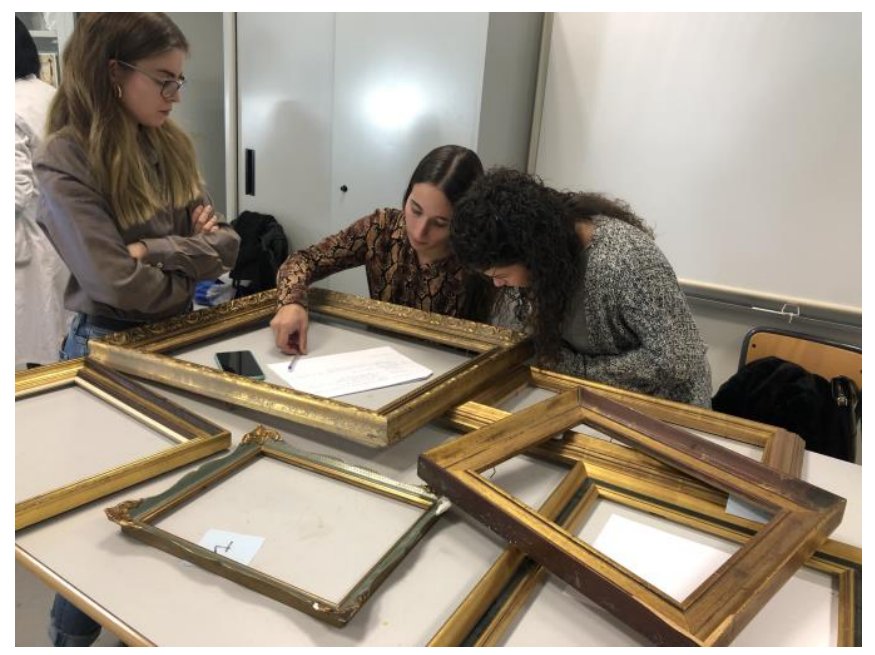

Fig. 2 Cooperative Learning Font: Own font 
Cooperative learning and brainstorming as didactic strategies in conservation and restoration of cultural assets

\subsection{Synthetic Phase}

1. Resolution of each specific case by the teacher.

When the students completed the activity, a pooling of the 15 groups, referring to the whole practice, was carried out, drawing a series of conclusions, which were being led by the teachers, coming to the resolution of each of the analyzed cases.

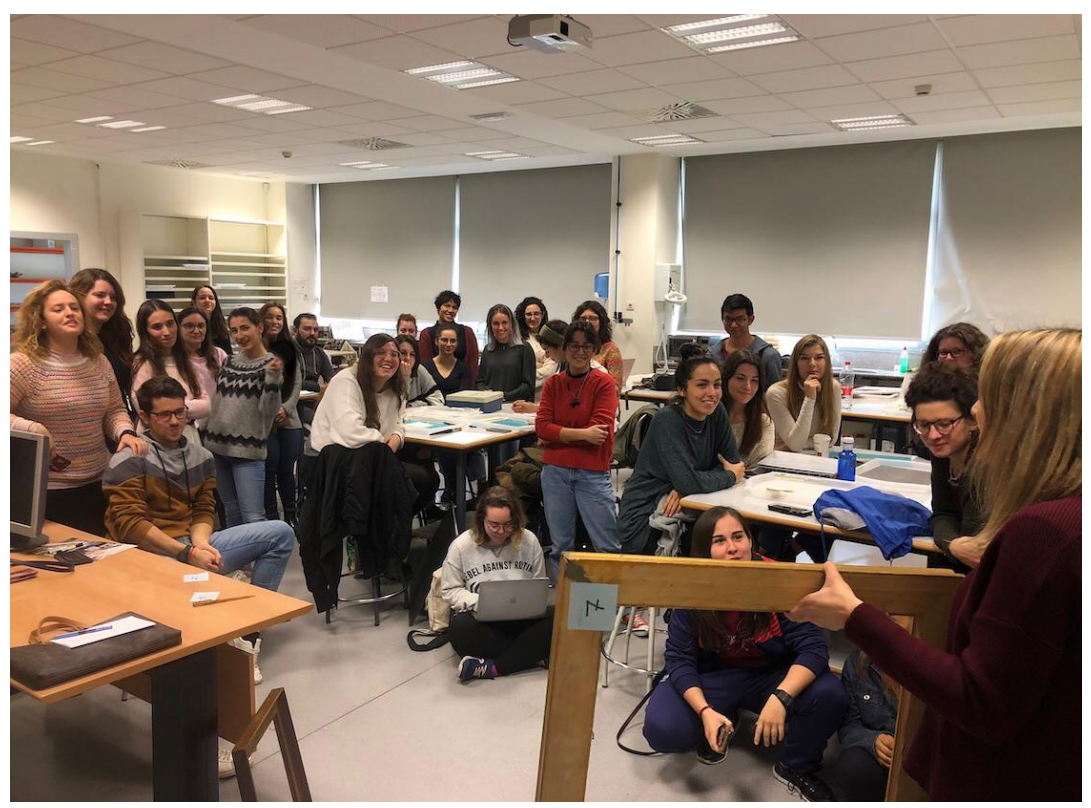

Fig. 3 Resolution of the practice

Font: Own font

2. Evaluation of results. The opinion of teachers and pupils was valued. The teacher qualified the practice, taking into account the transversal competences and competences that had been worked by each of the working groups. The transversal competences that have been worked in practice are: Understanding and integration, Innovation, and creativity.

3. Proposals for improvement. Based on the experience gained with the development of the practice and with the evaluation and analysis of results. 


\section{Results}

The present practice of identification of real tecniques within the subject of Conservation and Restoration of golds and polychromies, in the previous years had been been carried out in an individual way. The practice, when was carried out individually, was perceived by the students as very complex and of difficult resolution, to simple sight, without the capture of samples and analytical chemistries. The result of other years had not been so satisfactory for the teachers nor the students, given this complexity.With cooperative learning, the pupil feels leader of his own learning, his motivation has seen increased, meeting reflected in the resolution of the practice. It is important to stress that the complexity of approaches that the pupils were analyzing was great more advanced with the employment of cooperative learning. Likewise the worn out and acquired contents have been major to waited in beginning. With it, the interaction has been promoted among the pupils, the teamwork, the development of cooperative methodologies, leadership and the resolution of problems. In our case we can affirm that Johnsons's appointment was fulfilled, because what in previous years was one more practice of the subject, this year turned into an experience that the pupils to value in a positive way " The veers round of instructor is evolving from the presenter of information to the designer of learning experiences that maximize student activates engagement. The influences behind this change include the growing awareness that learning experiences should be activates in ways that maximize student engagement and the evidence that careful design of instructional experiences makes students ' acquisition of knowledge and competencies dwell efficient, effective, and appealing. One of the most useful methods of ensuring that students ploughs actively engaged in learning experiences is cooperative learning " (Johnson et to., 2018).

Other one of the results obtained of implementing this inclusive activity, is that the student body perceives that his opinion is born in mind, as strategy for the integration of contents, developing his practical and critical thought in real areas, promoting the efficient communication.

With this activity there has been promoted the equality of conditions, the diversity and the parity in the different resolutions related to the activity, the only routes for the collaborative work in the university classrooms.

\section{Conclusions}

The results obtained from the proposed activity show how peer learning is an effective, dynamic strategy with infinite possibilities. 
The fundamental improvement of Cooperative learning in disciplines in which teamwork and interdisciplinarity are the only routes in the real tasks of conservative professionals restorative, is that the students feel part of their own learning, developing specific valuable competences, in the achievement of proposals aimed at their future career.

Students' perception of brainstorming is always positive and motivating, but if a final response to the activity is not provided, it remains unfinished. By bringing the brainstormig together with the Cooperative learning, they understand that the processes developed in the classroom are aimed at solving real problems, with which they will meet when they leave the labour market.

The teaching methodology presented, however, is transferable to any university discipline, so special emphasis has been placed on the dissemination of the results of the experience in specialized media, for teachers interested in implementing the experience later.

\section{Acknowledgments}

To EICE “AFA-Realidad El proceso de Enseñanza y Aprendizaje Fuera de las Aulas Baños de Realidad", del Instituto de Ciencias de la Educación de la Universitat Politècnica de València, to provide a space in which to develop active and innovative methodologies.

\section{References}

Esteban González, L., Ortega Gutiérrez, J. (2017). "El debate como herramienta de aprendizaje" en VIII Jornada de Innovación e Investigación Docente 2017. Universidad de Sevilla. 48-56.

Johnson, D., \& Johnson, R. (2018). Cooperative Learning As The Foundation For Active Learning. In Active Learning. IntechOpen.

Ospina Rodríguez, J. (2006). "La motivación, motor del aprendizaje” en Revista Ciencias de la Salud, octubre, vol. 4, número Especial. Colombia. 158- 160.

Paulus, P. B., \& Kenworthy, J. B. (2019). Effective brainstorming. Handbook of Group Creativity: Innovation Through Collaboration, 287-386.

Rodríguez, G. B., \& Tenorio, F. L. (2005). Una concepción didáctica basada en el aprendizaje colaborativo para la educación de posgrado. Revista Cubana de educación superior, 23-37.

Guerra Santana, M. G., Pulido, J. R., \& Rodríguez, J. A. (2019). Aprendizaje colaborativo: experiencia innovadora en el alumnado universitario. REXE-Revista de Estudios y Experiencias en Educación, 17(35). 